\title{
Challenges of regional anaesthesia training: a prospective audit in a teaching orthopaedic hospital
}

Ayub K., Mann T., Mould M., Marfin A., Popat M., Galitzine S.

Nuffield Department of Anaesthesia, Oxford University Hospitals, Oxford, United Kingdom

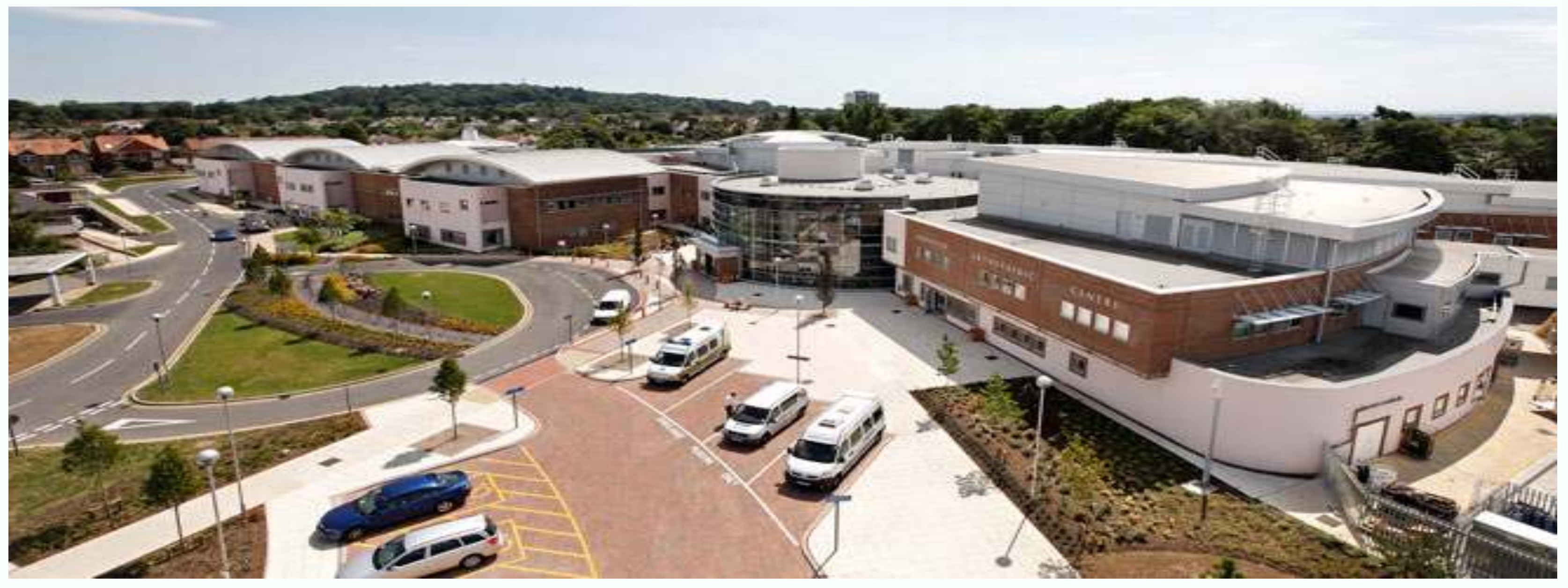

Background and Goal of Study: Advantages of regional anaesthesia (RA) for sole anaesthesia or supplemental analgesia are well known [1]. Achieving proficiency in its delivery requires time and training opportunities. It is estimated that a caseload of around 50 is required before procedural competence is achieved [2]. Whilst this can be attained via RA training modules, the need to match trainees with adequate exposure to RA techniques is essential for skill acquisition.

Materials and Methods: Data on elective orthopaedic operations have been prospectively collected at our teaching hospital, recording the cases with planned RA and the type of blocks. The presence of trainees, and whether they were working solo or doubled up with a Consultant or the senior organizing anaesthetist (SOA) was also identified.

Results and Discussion: We present the results of the first 6 months of this ongoing prospective audit. 2761 operations were scheduled across 823 theatre lists. This involved 1544 nerve blocks for 1313 patients: $643(41.6 \%)$ neuraxial, $713(46.1 \%)$ lower limb, 194 (12.6\%) upper limb and $3(0.2 \%)$ other blocks. Despite 1.9 nerve blocks performed per list, trainees were present at $160(19.4 \%)$ and doubled up with a non-SOA Consultant at only 69 (8.4\%) of the total lists (Table 1).
A clear discrepancy exists between training opportunities availability and trainee allocation. A greater number of trainees need to be allocated to elective lists and paired with a non-SOA Consultant more frequently. There remains an onus on trainees to rotate between theatres to increase exposure.

Table 1. Regional blocks vs trainee availability

\begin{tabular}{|l|l|l|l|l|l|l|}
\hline & $\begin{array}{l}\text { RA } \\
\text { cases }\end{array}$ & Blocks & Lists & $\begin{array}{l}\text { Blocks } \\
\text { /list }\end{array}$ & Trainee & $\begin{array}{l}\text { With } \\
\text { non- } \\
\text { SOA }\end{array}$ \\
\hline Total & 1313 & 1544 & 823 & 1.87 & $\begin{array}{l}160 \\
(19.4 \%)\end{array}$ & $\begin{array}{l}69 \\
(8.4 \%)\end{array}$ \\
\hline
\end{tabular}

Conclusions: This prospective audit has quantitatively confirmed our anecdotal impression that training opportunities are not fully utilised. We will highlight this shortfall to our department and reevaluate training experience over the next six months.

\section{References:}

1. Mingus $M$. Recovery advantages of regional anaesthesia compared with general anaesthesia. JCA 1995; 7(7):628-633.

2. Kopacz $D$. The regional anaesthesia "learning curve". What is the minimum number of epidural and spinal blocks to reach consistency? Regional Anaesthesia 1996; 21(3):182-90. 